\title{
Akreditasi, Keunggulan Penciri, dan Alih Status Kelembagaan: Penyiapan Kultur Akademik Mewujudkan Ekosistem Keilmuan Perguruan Tinggi*
}

\author{
Ismail Suardi Wekke \\ Sekolah Tinggi Agama Islam Negeri (STAIN) Sorong, Indonesia \\ University College of Yayasan Pahang, Malaysia \\ Email: ismail@stain-sorong.ac.id
}

\begin{abstract}
ABSTRAK
Artikel ini menjadi sebuah catatan sekaitan dengan pelaksanaan akreditasi. Terdapat dua hal yang perlu diperhatikan yaitu keunggulan penciri dan kultur akademik. Jika ini dikembangkan, maka pada akhirnya perguruan tinggi akan membentuk ekosistem keilmuan. Masing-masing bagian saling terkait sehingga memiliki keeratan antara satu dengan yang lain. Maka, ada dua hal yang menjadi kunci semuanya konsistensi dan juga kolaborasi.
\end{abstract}

Kata Kunci: pendidikan tinggi; ekosistem keilmuan; perguruan tinggi.

\section{Pendahuluan}

Perguruan tinggi bukanlah entitas yang terpisah dari masyarakat. Dengan beragamanya populasi perguruan tinggi (Abes, 2005), maka ini sebuah cerminan bahwa perguruan tinggi memiliki keluasan gerak dan potensi gerakan. Termasuk, perguruan tinggi sesungguhnya adalah kesempatan untuk menjalankan ibadah. Secara khusus, Dien Syamsuddin mengemukakan bahwa akreditasi bukanlah dalam rangka secara khusus untuk mendapatkan status unggul, tetapi merupakan bagian dalam rangka meraih Ridho Allah SWT. ${ }^{1}$ Dengan demikian, penyusunan borang tidak dimungkinkan untuk ditulis dengan bohong dan ngarang. Karena ini adalah proses untuk mendapatkan Ridhol Allah. Sementara itu, dengan mengenali kriteria penilaian bukan menjadi kesempatan untuk membuat bukt fisik yang dikerjakan dalam semalam ketika menunggu visitasi. Melainkan untuk membangun kultur akademik di perguruan tinggi.

Universitas Al Azhar dengan kukuh memegang tradisi keilmuan yang dibangun berabad-abad lamanya. Dengan kekukuhan itu, menjadi salah satu sarana ilmu pengetahuan dunia Islam. Walaupun tidak diabsen, dan dosen secara terjadwal menyampaikan kuliah di masjid Al Azhar justru ini menjadi sarana dalam proses transmisi pengetahuan. Bukan sebuah kewajiban, tetapi mahasiswa akan merasa kurang jikalau tidka mengikuti kajian-kajian yang dilaksanakan di masjid. Tidak hanya itu saja, masjid-masjid

* Artikel ini merupakan catatan seusai Focus Group Discussion, Pascasarjana Sekolah Tinggi Agama Islam Negeri (STAIN) Sorong, Indonesia; 29 Juli 2019. Walaupun merupakan FGD namun secara keseluruhan merupakan catatan pribadi penulis. Baik peserta maupun institusi pascasarjana sendiri bukanlah pihak yang memberikan otoritas dalam penulisan artikel ini, sekaligus bukan dokumen pascasarjana STAIN Sorong.

${ }^{1}$ Disampaikan dalam Seminar Nasional Badan Kerjasama Perguruan Tinggi Islam Swasta, Universitas Muhammadiyah Jakarta, 11-12 Juli 2019. 
seentaro kota Kairo juga melaksanakan pengajian dengan topik-topik secara spesifik. Pengajian di masjid luar universitas juga diasuh oleh dosen-dosen Azhar. ${ }^{2}$ Begitu pula, masjid di Alexandria juga mengukuhkan ritual tarekat yang menjadi bagian dari implementasi tanggungjawab dosen Azhar. Sebagai bagian dari tradisi kearaban, Al Azhar juga memiliki tanggung jawab untuk menumbuhkembangkan bahasa Arab dalam kerangka pemahaman keislaman (Rugh, 2002; Merriam, 1974; Hatina, 2003).

Menuju pada capaian itu, artikel ini secara khusus mengidentifikasi pokok-pokok pikiran terkait dengan tiga hal untuk mewujudkan ekosistem keilmuan perguruan tinggi. Termasuk menegaskan kembali akhirat class university sebagai salah satu tipologi perguruan tinggi.

\section{World Class University versus Akhirat Class University}

Sejak awal pembentukan perguruan tinggi bukanlah dalam rangka meraih rangking. Namun, keberadaan perguruan tinggi semata-mata untuk melayani keperluan masyarakat. Maka, tipikal perguruan tinggi tidaklah tunggal. Bisa jadi perguruan tinggi dengan wawasan regional, perlu menggunakan kriteria Akhirat Class University (Wekke, 2019). Tidak semua perguruan tinggi perlu diarahkan untuk memenuhi kriteria riset melainkan juga perlunya memenuhi keperluan warga setempat. Sebuah penelitian seperti yang dilakukan Geertz (1976) tentang Jawa, secara kasat mata tidak memberikan sumbangan apa-apa bagi masyarakat Jawa sendiri. Sehingga diperlukan pendekatan lain yang tidak hanya terkait dengan riset semata.

Sebagaimana perguruan tinggi di Papua memiliki orientasi terhadap lingkungannya, maka perlu dirumuskan strategi pengembangannya tersendiri (Wekke, Kahar, \& Amri, 2018). Dengan tetap terbangun dalam kerangka pendidikan nasional, maka perlahan pendidikan tinggi Papua akan memiliki daya sanding secara nasional bahkan global (Wekke, 2018). Keterbatasanketerbatasan yang ada bukanlah menjadi alasan untuk tidak bisa mencapai kemajuan. Justru dengan keterbatasan itu, tetap menumbuhkan semangat untuk turut memberikan kesempatan pendidikan tinggi yang unggul (Wekke, 2013).

Terkait dengan kelas yang menjadi aktivitas rutin mahasiswa dan dosen, perlu diintegrasikan dengan kegiatan penelitian dan pengabdian masyarakat. Bahkan untuk itu, perlu dinyatakan secara khusus dalam mata kuliah tertentu. Strategi mewujudkan ini, dijalankan dalam bentuk kolaborasi antar dosen dan mahasiswa dengan menggunakan teknik penyelarasan. Justru ini menjadi kesempatan untuk menjadi leading dalam kajian

${ }^{2}$ Observasi dilaksanakan sepanjang pekan pertama Februari 2019 di Kairo dan Alexandria, Mesir. 
Islam terkemuka secara global (Wekke, 2018). Pendidikan tinggi Islam di Indonesia perlu dilakukan reformulasi sehingga dapat memainkan peran di tingkat regional dan mulai memikirkan pengenalan ke seentaro dunia Islam .

Teknologi informasi dan komunikasi hanyalah sebagai media pembelajaran semata. Namun, tak dapat diabaikan sama sekali. Justru tetap ada kesempatan untuk melaksanakan blended learning (Garrison \& Kanuka, 2004). Namun, secara berkala perlu dilakukan sosialisasi sekaligus aktivitas untuk memperkenalkan penggunaan-nya. Tanpa itu, hanya dengan melakukan trial and error yang justru tidak menjadikan pemanfaatan waktu yang efisien.

Bagian yang tak kalah pentingnya, keberagamaan dan tradisi beragama yang tetap perlu dijadikan sebagai acuan utama (Wekke, Hermawanto, \& Ashrori, 2016; Hermawanto, Ashrori, \& Wekke, 2019). Justru di perguruan tinggi menjadi kesempatan untuk tetap menumbuhkembangkan tradisi beragama di masyarakat. Pada saat yang sama, diperlukan kajian antropologi sehingga tidak saja menjadi living culture tetapi juga publikasi terkait dengan budaya yang dipraktikkan tersebut. Hidayat (2014) mengemukakan dengan istilah suasana religious kampus. Ini menjadi salah satu parameter keberadaan perguruan tinggi Islam. Universitas Islam Negeri Maulana Malik Ibrahim Malang menunjukkan bahwa dengan tetap menjadikan tradisi Islam yang melingkupi wilayah perguruan tinggi, maka kesempatan untuk mengembangkan pengetahuan juga tetap terbuka (Mulyono \& Wekke, 2018). Pada saat yang sama perguruan tinggi juga menjadi instrument untuk menjaga harmoni keberagamaan (Mujahidah \& Wekke, 2019).

\section{Akreditasi dan Tantangan Alih Status}

Dua hal yang berbeda, namun dapat dikerjakan secara bersama. Ketika proses dan langkah yang terkait menuju akreditasi dilaksanakan, ini akan menjadi kesempatan untuk mempersiapkan alih status kelembagaan. Ketika akreditasi dijadikan sebagai instrument untuk mempersiapkan ekosistem keilmuan, maka ini akan menjadi kesempatan pada tahapan berikutnya untuk melakukan pengembangan. Hanya saja, paradigm keilmuan dan pengembangan integrasi Islam dan pengetahuan perlu menjadi catatan utama (Abbas \& Wekke, 2019).

Bagian terpenting yang perlu diperhatikan adalah dosen. Dosen tidaklah menjadi benda mati tetapi justru menjadi bagian dari masyarakat. Ketika dosen menjalankan tri dharma perguruan tinggi, maka semua rekam jejak kinerja yang ada dapat dicatatkan dalam borang. Sebaliknya, jika tidak ada rekam jejak terutama jika tidak menggunakan 
flatform digital, ini akan menjadi tantangan tersendiri. Sebagai contoh penggunaan repository. Salah satu sarana memudahkan pencarian dengan menggunakan indeks. Fasilitas yang paling mudah digunakan diantaranya Google Scholar. Maka, perlu diidentifikasi penggunaan platform repository yang dapat terhubung dengan Google Scholar.

Perubahan kelembagaan semata-mata hanya terkait dengan kebijakan politik penguasa. Niam (2011) justru melihat terkadang aturan bahkan dilanggar dan tidak dijadikan sebagai panduan sama sekali. Bahkan pasca alih status sebuah perguruan tinggi tidak memberikan kesempatan untuk adanya pengembangan keilmuan Islam. Justru program studi keagamaan tidak mengalami kemajuan berarti. Justru program studi sains yang mengalami perkembangan (Rais, 2017). Juga, tidak telihat pendekatan dan teknik untuk melakukan integrasi keilmuan.

Bukan berarti bahwa ketika sebuah perguruan tinggi sudah established lalu tidak memiliki tantangan sama sekali. Bahkan Al Azhar sekalipun tetap memiliki dinamika internal dan juga eksternal dalam lingkup Mesir dan dunia Islam (Zeghal, 1999). Untuk itu kepempinan perguruan tinggi perlu menggerakkan setiap komponen yang ada untuk memungkinkan mendukung visi yang dicanangkan bersama. Universitas juga terkadang melupakan pendidikan yang justru merupakan core aktivitas pendidikan tinggi (Lewis, 2006; Ding-kai, 2008; Tull, 2007). Mencapai semua keunggulan tidak berari serta merta meninggalkan aspek-aspek sosial yang menjadi bagian kemanusiaan itu sendiri (Rockquemore \& Laszloffy, 2008).

\section{Penutup}

Pertanyaan pertama dalam mengurus perguruan tinggi adalah "kemana arah perguruan tinggi hendak dibawa?". Ketika ini terjawab, maka dengan mudah strategi dan langkah menuju visi itu dapat diwujudkan. Selanjutnya, tindak lanjut dari setiap aktivitas untuk memudahkan pencapaian visi yang sudah dicanangkan. Sementara itu, penyusunan visi tidak terkait dengan kepemimpinan yang temporer tetapi merupakan visi yang akan wujud dalam waktu yang panjang. Maka, ini akan kembali ke awal bahwa pengurusan perguruan tinggi semata-mata dalam rangkaian menjaga khittah kemanusiaan yang diemban setiap orang untuk menghambakan diri kepada-Nya. 


\section{Daftar Pustaka}

Abbas, T., \& Wekke, I. S. (2019, May 16). Yang Datang Setelah Hujan: Sains-Agama Penerang Kegelapan. https://doi.org/10.31227/osf.io/nfx4v.

Abes, E. S. (2005). Identity development of diverse populations: Implications for teaching and administration in higher education.

Ding-kai, H. O. U. (2008). The First-class Institutions that don't Offer the Best Education: Some Reflections on Excellence without a Soul [J]. In Fudan Education Forum (Vol. 1).

Garrison, D. R., \& Kanuka, H. (2004). Blended learning: Uncovering its transformative potential in higher education. The internet and higher education, 7(2), 95-105.I

Geertz, C. (1976). The religion of Java. University of Chicago Press.

Hatina, M. (2003). Historical Legacy and the Challenge of Modernity in the Middle East: The Case of al-Azhar in Egypt. The Muslim World, 93(1), 51-68.

Hermawanto, A., Ashrori, M., \& Wekke, I. S. (2019). Tradisi Keislaman di Perguruan Tinggi. https://doi.org/10.31227/osf.io/29hba.

Hidayat, M. U. (2014). Persepsi warga kampus STAIN Datokaramapalu tentang penciptaan suasana religius kampus untuk menunjang pencapaian kualitas akademik (Menyongsong alih status kelembagaan STAIN Menjadi IAIN). Istiqra: Jurnal Hasil Penelitian, 2(1), 124.

Lewis, H. R. (2006). Excellence without a soul: How a great university forgot education (pp. 1995-2003). New York: PublicAffairs.

Merriam, A. H. (1974). Rhetoric and the Islamic tradition. Communication Quarterly, 22(1), 4349.

Mujahidah, M., \& Wekke, I. S. (2019). Transformasi Perguruan Tinggi Keagamaan Islam Indonesia. https://doi.org/10.31227/osf.io/46evm.

Mulyono, M., \& Wekke, I. S. (2018). Academic and Culture Development Strategy Management for Islamic Higher Education in Indonesian. IOP Conference Series: Earth and Environmental Science (Vol. 175, No. 1, p. 012163). IOP Publishing.

Ni'am, S. (2011). Menimbang Kembali Pendekatan Kajian Keislaman di Perguruan Tinggi Agama Islam. Al-Tahrir: Jurnal Pemikiran Islam, 11(2), 349-370.

Rais, M. (2017). Kapasitas UIN Alauddin Makassar pasca alih status. EDUKASI: Jurnal Penelitian Pendidikan Agama dan Keagamaan, 15(3).

Rockquemore, K., \& Laszloffy, T. A. (2008). The black academic's guide to winning tenure-without losing your soul (p. 261). Boulder, CO: Lynne Rienner Publishers.

Rugh, W. A. (2002). Arab education: Tradition, growth and reform. The Middle East Journal, 396-414.

Tull, A. (2007). Excellence Without a Soul: How a Great University Forgot Education. Journal of College and Character, 8(4).

Wekke, I. S. (2013). Merawat Semangat Mengatasi Keterbatasan. Menuju Indonesia Berkeadilan. Jakarta: Indonesia Social Justice Network, 207-228.

Wekke, I. S. (2018). Higher education governance of muslim minority: efforts to be part of nation's development. AKADEMIKA: Jurnal Pemikiran Islam, 23(1), 1-26.

Wekke, I. S. (2018). Masa Depan Kajian Islam di Indonesia. https://doi.org/10.31227/osf.io/36tua.

Wekke, I. S. (2019). Menata Saat Kini untuk Masa Hadapan: Agenda Transformasi Dari STAIN Ke IAIN. https://doi.org/10.31227/osf.io/d83es.

Wekke, I. S., Hermawanto, A., \& Ashrori, M. (2016). Keberagamaan Mahasiswa Di Perguruan Tinggi Wilayah Minoritas Muslim. Ulul Albab, 17(2), 135.

Wekke, I. S., Kahar, M. S., \& Amri, I. (2018). Perguruan Tinggi Tanah Papua Dan Strategi Pengembangan Pendidikan Tinggi. https://doi.org/10.31227/osf.io/m3kvb.

Zeghal, M. (1999). Religion and politics in Egypt: The ulema of al-Azhar, radical Islam, and the state (1952-94). International Journal of Middle East Studies, 31(3), 371-399. 